\title{
Yield and Chemical Composition of Spring Wheat Harvest on Oil-contaminated Grey Forest Soil
}

\author{
Minnegali Gilyazov, Regina Osipova, Amir Ravzutdinov, and \\ Svetlana Kuzhamberdieva \\ Kazan State Agricultural University, Kazan, Russia
}

\section{Abstract}

The study was carried out in the Republic of Tatarstan (Povolzhsky Federal District of the Russian Federation) in the conditions of grey forest medium loamy soil with weakly acidic reaction of the environment, low humus content, increased and average content of mobile forms of phosphorus and potassium respectively. The soil was intentionally polluted with oil at the rate of 10,20 and $40 \mathrm{l} / \mathrm{m}^{2}$. Close negative correlation of spring wheat yield from oil dose $\left(R^{2}=0,945 \ldots 0,997\right)$ and positive dependence on the statute of limitations of single soil contamination $\left(R^{2}=0,713 \ldots 0,993\right)$ was established. The possibility of gradual, though slow, natural elimination of phytotoxicity of oil-contaminated grey

Corresponding Author:

Minnegali Gilyazov

Received: 25 October 2019

Accepted: 15 November 2019

Published: 25 November 2019

Publishing services provided by

Knowledge E

(c) Minnegali Gilyazov et al. This article is distributed under the terms of the Creative Commons Attribution License, which permits unrestricted use and redistribution provided that the original author and source are credited.

Selection and Peer-review under the responsibility of the AgroSMART 2019 Conference Committee. forest soil without special methods of recultivation is noted. The content of nitrogen, phosphorus and potassium in spring wheat plants under the influence of oil pollution has not changed significantly, but accumulation of carcinogenic substances in them was found. It is indicated that for the objective assessment of detoxification of oil-contaminated soils it is necessary to take into account not only the productivity of plants, but also to study in depth the chemical composition of the crop.

\section{Introduction}

Oil and petroleum products are the most common pollutants in the environment, including soil cover $[1,3,8,9]$. Pollution of land with oil and oil products has a complex negative impact on the soil, worsening its agrochemical, agrophysical, biological properties $[2,3,8,11,12]$, and directly oppressing the plant itself $[4,7,10]$. in the end, oil pollution leads to the total or partial death of crops for many years. However, in some cases, in some cases, oil substances have stimulated plant growth [5]. Conflicting information about the influence of oil pollution on plant productivity and poor illumination of its effect on the chemical composition of the crop [3,6], served as an impulse for our study.

\section{G OPEN ACCESS}




\section{Materials and Methods}

The research was carried out in 2004--2017 in the pilot field of Kazan State Agrarian University, located in the pre-Cameroon agro-production zone (Predkamye) of the Republic of Tatarstan (RT). The Predkamye of the Republic of Tatarstan occupies the northern part of the republic: the Predkamye River is limited to the southwest of the country. It is located in the Volga River, in the south -- in the Kama River. The relief is a low, dumpy plain, the highest altitude of which reaches $240 . .280 \mathrm{~m}$. Its area is 21.8 thousand $\mathrm{km} 2$, which is $32.2 \%$ of the total area of the Republic of Tajikistan. The main part (67\%) of the agricultural lands of the Predkamsk zone is located on various subtypes of grey forest soils.

In terms of thermal resources, the Predkamye region belongs to the temperatecool zone of the republic: the average annual air temperature is $2.5{ }^{\circ} \mathrm{C}$, the sum of temperatures above $10{ }^{\circ} \mathrm{C}$ is 2150 . Annual precipitation is $440 \mathrm{~mm}$. The amount of precipitation during the growing season varies within the limits of $245 \ldots 265 \mathrm{~mm}$, the hydrothermal coefficient (HTC) is slightly higher than one. Average duration of vegetation period is 160 days, average thickness of snow cover is $39 . .44 \mathrm{~cm}$.

Vegetation periods in the years of spring wheat cultivation differed significantly in terms of the main meteorological indicators -- average monthly air temperature and amount of precipitation. The most favorable weather conditions were in 2009 and 2005, while the least favorable ones were in 2013. In particular, in June 2013, the high air temperature was accompanied by a large deficit of precipitation (37\% of the multiyear average) during the whole month, and in 2005 , the June precipitation exceeded the mean multiyear values by 1.6 times with a favorable temperature regime. In the Predkamye region of Tajikistan, as our research has shown, June precipitation largely determines the productivity of spring wheat.

Soil of the pilot plot is grey forest middle-loam with weakly acidic reaction $(\mathrm{pH}=5.4)$. Before oil pollution (May 2004), it had a low humus content (2.91\%), an increased content of mobile phosphorus (129 mg/kg) and an average of mobile potassium (115 mg/kg).

Field trial plots are bottomless boxes deepened in the soil to a depth of $30 \mathrm{~cm}$. The plot area is $0.50 \mathrm{~m}^{2}$, the width of the protective strips is $1 \mathrm{~m}$. Repetition of the experience is fourfold. To pollute the soil, we used commercial oil prepared by Jalilneft Oil and Gas Production Department (NGDU) with the following parameters: density at $20^{\circ} \mathrm{C}-0.885$ $\mathrm{g} / \mathrm{cm}^{3}$, mass fraction of water $-0.06 \%$, mass fraction of sulfur $-3.08 \%$, concentration of chloride salts -- $37 \mathrm{mg} / \mathrm{dm}^{3}$. Soil was intentionally polluted in May 2004 from расчlета 
10, 20 and 40 liters of commercial oil per $1 \mathrm{~m}^{2}$. These doses, as our previous studies have shown, correspond to low, medium and high levels of contamination.

The effect of oil pollution on crop productivity was studied in crop rotation: spring wheat -- barley -- spring rape -- millet. This report summarizes information on the impact of oil pollution on the yield of soft spring wheat (Triticumaestivum L.), which was cultivated according to the crop rotation scheme, 1, 5, 9 and 13 years after the oil contamination of the soil. Seeding rate was 5.5 million germplasm seeds per hectare, seed placement depth was $5 \mathrm{~cm}$. All works in experience were performed manually, adhering to the zonal agricultural machinery to the maximum extent possible.

\section{Results and Discussion}

The data in Table 1 show a strong negative impact of single oil pollution on the yield of spring wheat during the whole period of observation. There was a very noticeable dependence of the yield on two factors on the polluted soil: the oil dose and the age of contamination. In this case, the term "age of contamination" should be understood to mean the length of time elapsed from the moment of soil contamination to the sowing of agricultural crops.

TABLE 1: Influence of single oil pollution of grey forest soil on grain and spring wheat straw yield and longevity.

\begin{tabular}{|c|c|c|c|c|}
\hline \multirow[t]{3}{*}{ Oil dose, $1 / \mathrm{m}^{2}$} & \multicolumn{4}{|c|}{ Years and years of contamination* } \\
\hline & 2005 (1 year) & $2009(5$ years $)$ & 2013(9 years) & 2017(13 years) \\
\hline & \multicolumn{4}{|c|}{ Yield of grain, $\mathrm{g} / \mathrm{m}^{2}$} \\
\hline 0 -- control & $\underline{262} 100$ & $\underline{289} 100$ & $\underline{193100}$ & $\underline{242} 100$ \\
\hline 10 & $\underline{114} 44^{* *}$ & $\underline{150} 52$ & $\underline{16284}$ & $\underline{215} 89$ \\
\hline 20 & $\underline{0} 0$ & 6121 & 10353 & $\underline{18175}$ \\
\hline 40 & $\underline{0} 0$ & $\underline{6} 2$ & $\underline{56} 29$ & $\underline{111} 46$ \\
\hline $\operatorname{MED}_{05}\left(\mathrm{~g} / \mathrm{m}^{2}\right)$ & 22 & 19 & 11 & 15 \\
\hline \multicolumn{5}{|c|}{ Straw yields, $\mathrm{g} / \mathrm{m}^{2}$} \\
\hline 0 -- control & $\underline{304} 100$ & $\underline{335} 100$ & $\underline{208} 100$ & $\underline{250} 100$ \\
\hline 10 & $\underline{20166^{* *}}$ & $\underline{224} 67$ & 18388 & $\underline{232} 93$ \\
\hline 20 & $\underline{0} 0$ & $\underline{110} 33$ & $\underline{16378}$ & $\underline{220} 88$ \\
\hline 40 & $\underline{0} 0$ & 309 & $\underline{154} 74$ & 14357 \\
\hline $\operatorname{MED}_{05}\left(\mathrm{~g} / \mathrm{m}^{2}\right)$ & 27 & 23 & 13 & 19 \\
\hline
\end{tabular}

Note: * -- contamination time -- time elapsed from the moment of soil contamination to the sowing of agricultural crops; ${ }^{* *}--$ numerator in $\mathrm{g} / \mathrm{m}^{2}$; denominator -- percentage of the control level. 
To illustrate the close dependence of spring wheat productivity on oil doses, it is enough to look at the yield of spring wheat in 2017, sown 13 years after a single contamination. Thus, if on the control (uncontaminated) soil grain yield was $242 \mathrm{~g} / \mathrm{m}^{2}$, on soils that received 10,20 and $40 \mathrm{l} / \mathrm{m}^{2}$ of oil, it was 215,181 and $111 \mathrm{~g} / \mathrm{m}^{2}$, respectively. The presence of close negative dependence of grain yield and spring wheat straw on oil doses is illustrated by the graphs in Fig. 1.

Between the doses of oil and the yield of grain and straw in spring barley there was a close negative dependence, as evidenced by the trend line and the value of the coefficients of determination $\left(R^{2}\right)$. The correlation closely did not decrease with the aging of oil pollution. The coefficients of determination of grain and spring wheat straw yield from oil doses ranged from 0.7305 to 0.9973 .

Let's consider the character of action of another factor, which had a strong influence on the yield of spring wheat on oil-contaminated soil -- the age of contamination. In the conditions of our experiment the limitation of oil pollution fluctuated from one to 13 years (table 1).

One year after the pollution (2005) the yield was obtained only on slightly polluted soil $\left(10 \mathrm{l} / \mathrm{m}^{2}\right)$. From this minimum dose grain yield decreased by $56 \%$, and straw -- by $34 \%$, in connection with what the ratio of "straw: grain" has expanded: if on the control it was equal to 1,16, on the oil-contaminated soil -- 1,76. At the next two levels of oil pollution $\left(20\right.$ and $40 \mathrm{l} / \mathrm{m}^{2}$ ) the seeds of spring wheat did not ascend.

In 2009, the seeds of spring wheat did not climb up. (5 years old) spring wheat plants appeared at all three levels of contamination, which indicates a marked decrease in soil phytotoxicity over the past 5 years after contamination. Thus, if the average level of pollution $\left(20 \mathrm{l} / \mathrm{m}^{2}\right)$ in 2005 was not a yield, then in 2009 in relation to the control the yield of grain and straw was 21 and $33 \%$, respectively.

In 2009--2013, the relative yield (as a percentage of the level of control) at all three levels of pollution increased by about $27--32 \%$, bringing the yield of spring wheat grains on lightly polluted soil quite close to the benchmark level (84 \%) in 2013.

The wheat yield data for 2017 confirms the earlier trend of a gradual increase in relative yields as the age of contamination increases. In 2017, grain yields, especially straw, came close to the benchmark level (uncontaminated soil). At the same time, the decrease in grain yields, even from low pollution, remained statistically reliable.

Thus, the yield data of 2005, 2009, 2013 and 2017 indicate a gradual detoxification of oil-contaminated grey forest soil in the Predkamye region of the Republic of Tatarstan without any methods of recultivation at all tested levels of pollution (10, 20 and $40 \mathrm{l} / \mathrm{m}^{2}$ ). 


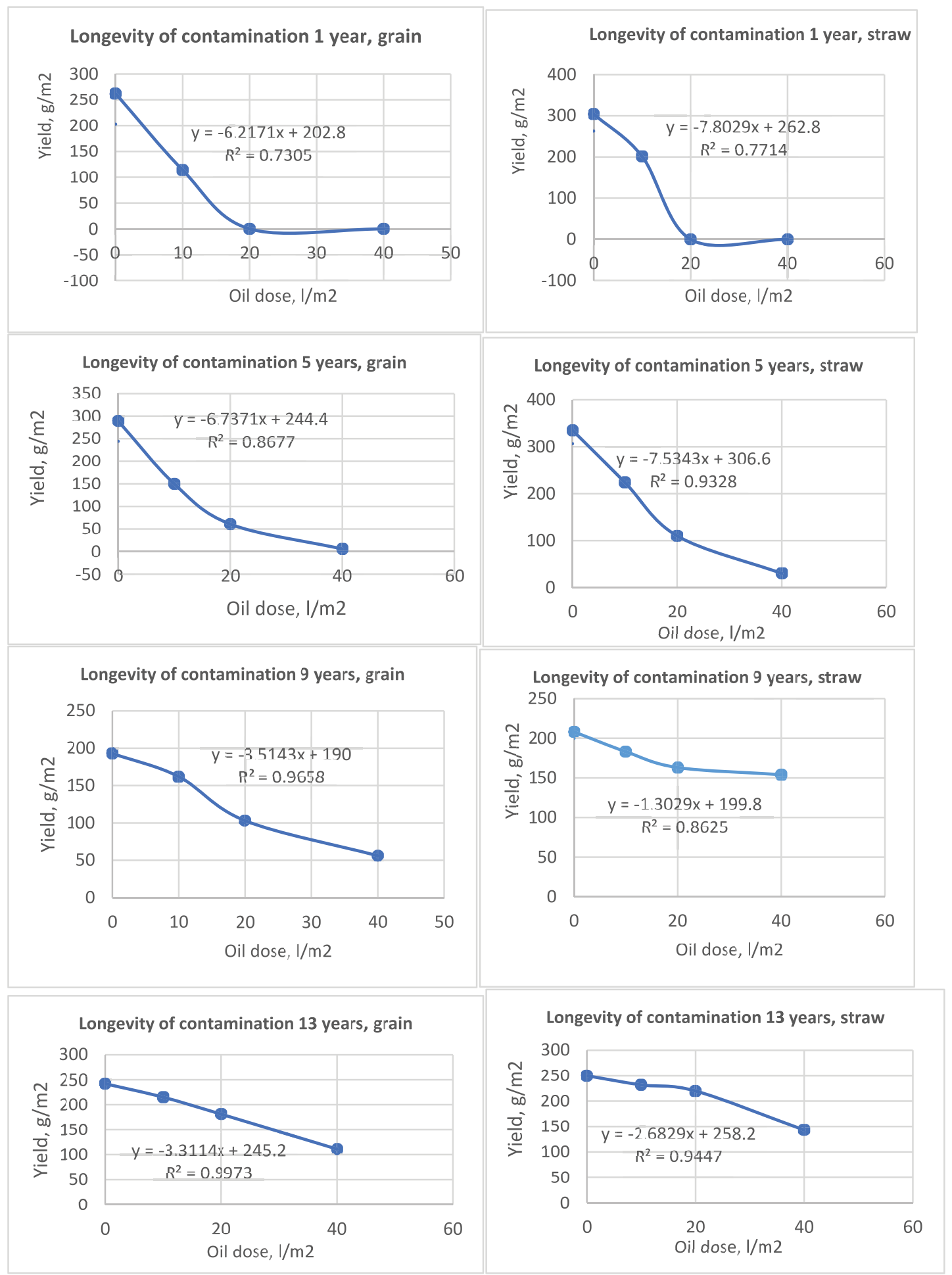

Figure 1: Dependence of spring wheat yield on oil doses in grey forest soils.

The most obvious gradual approach of spring wheat yield on oil-contaminated soils to the level of control (uncontaminated soil) is illustrated by the materials of Figure 2 . 
As it can be seen, there is a very close positive dependence of spring wheat yield on the age of oil pollution. As the oil pollution aging, the yield of grain and straw gradually increased. During all the years of research, the yield of straw increased at a higher rate. The coefficients of determination $\left(\mathrm{R}^{2}\right)$ of grain yield from the age of contamination, depending on the initial level of contamination, ranged from 0.913 to 0.993. In the same way, oil pollution prescription also influenced the yield of straw $\left(R^{2}=0.713 \ldots 0.951\right)$.

Thus, the negative impact of single oil pollution of grey forest soil at the rate of 10 , 20 and 40 liters $/ \mathrm{m}^{2}$ on the yield of wheat has manifested itself during 13 years, at the same time, the approach of yields to the level of control, which indicates the possibility of gradual elimination of phytotoxicity of oil-contaminated soil without recultivation.

The analysis of data on the influence of single oil contamination of grey forest soil with doses of 10,20 and $40 \mathrm{l} / \mathrm{m}^{2}$ on the structure of spring wheat yield showed that the decrease in grain yield was caused by deterioration of all elements of the yield structure: the number of plants and ears per unit area, the number of grains in the ear and the weight of 1000 grains (Table 2). Depending on the initial level of oil pollution, the rates of reduction of these crop structure indicators were different. From the minimum dose of oil $\left(10 \mathrm{l} / \mathrm{m}^{2}\right)$ all four elements of the yield structure decreased in approximately the same degree. The average dose of oil $\left(20 \mathrm{l} / \mathrm{m}^{2}\right)$ had the greatest reduction in the number of plants and ears per unit area. In the case of soil contamination with the maximum dose of oil $\left(40 \mathrm{l} / \mathrm{m}^{2}\right)$, the number of grains in the ear and the number of ears per unit area decreased the most. At all levels of soil contamination, oil had the least impact on the mass of 1,000 grains.

TABLE 2: Impact of old oil pollution on spring wheat harvest structures (2017).

\begin{tabular}{|l|c|c|c|c|}
$\begin{array}{l}\text { Experiment } \\
\text { variants }\end{array}$ & $\begin{array}{c}\text { Number of plants, } \\
\text { pcs. } / \mathrm{m}^{2}\end{array}$ & $\begin{array}{c}\text { Number of spikes, } \\
\text { pcs. } / \mathrm{m}^{2}\end{array}$ & $\begin{array}{c}\text { Number of grains } \\
\text { in spike, pcs. }\end{array}$ & $\begin{array}{c}\text { Weight: } 1000 \\
\text { grains, } \mathrm{g}\end{array}$ \\
\hline 0 -- control & 344 & 351 & 18.0 & 38.3 \\
\hline 10 & 329 & 337 & 17.2 & 37.1 \\
\hline 20 & 304 & 305 & 16.3 & 36.3 \\
\hline 40 & 271 & 266 & 13.2 & 31.6 \\
\hline
\end{tabular}

Note: ${ }^{*}$ the age of contamination is 13 years.

When assessing the impact of oil pollution on crops, it is important to know not only the change in yield, but also the chemical composition of the crop. Under the influence of the old oil pollution the content of nitrogen, phosphorus and potassium in the plants of spring wheat did not decrease, on the contrary, a tendency of its weak increase was revealed, however, these changes appeared to be statistically insignificant (Table 3). Thus, the oil pollution of 13 years ago did not have a significant influence on the content 


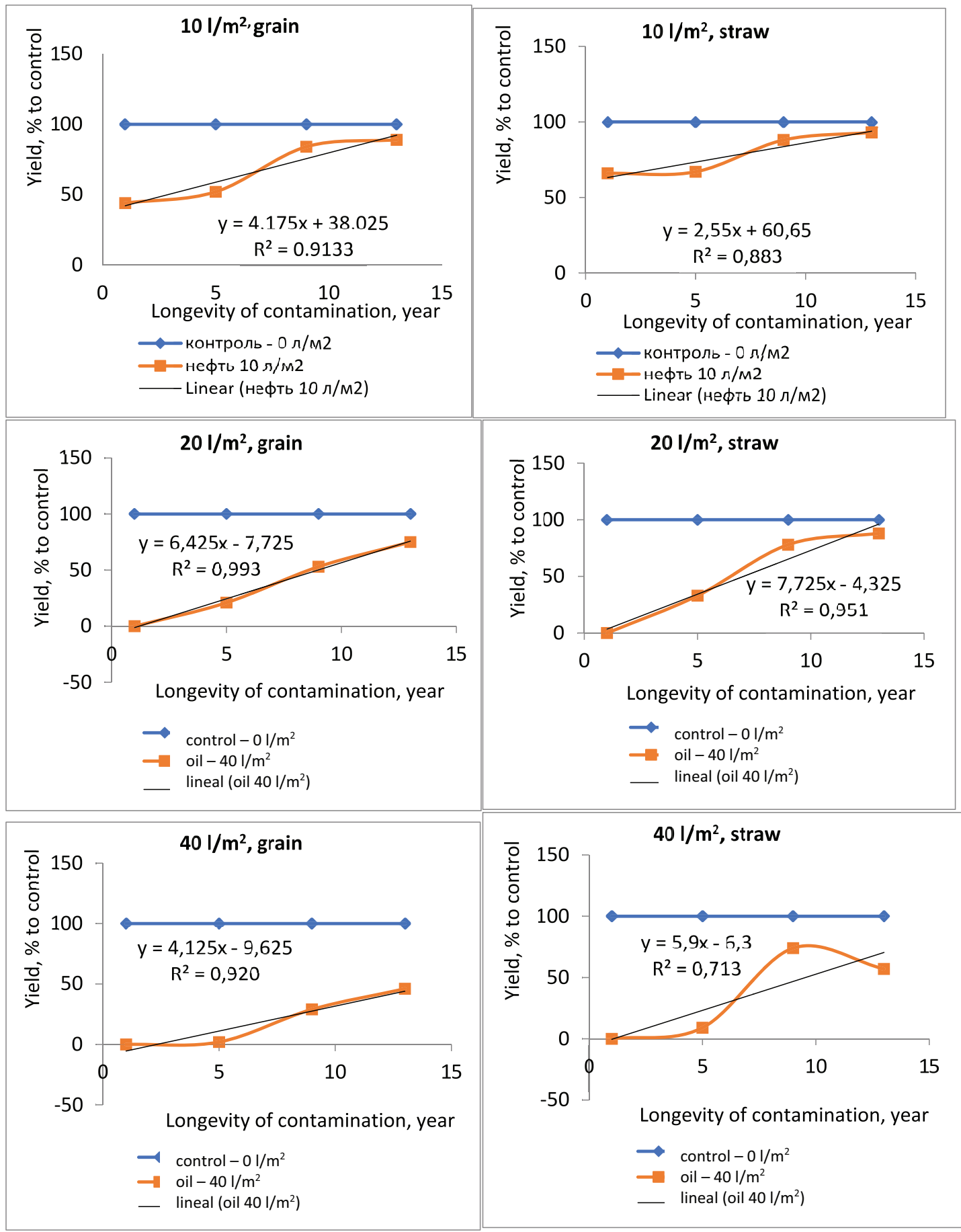

Figure 2: Correlation of spring wheat yield from the age of oil contamination of forested soils (2005--2017).

of nitrogen, phosphorus and potassium in the crop, but it had a strong influence on the content of a number of substances with a significant carcinogenic potential.

The study revealed the presence of five benzo(a)pyrene homologists in spring wheat grain: 5-methylchrysene, dibenzo(a,h)anthracene, chrysene, indeno[1,2,3-c,d]pyrene, 
TABLE 3: Total nitrogen, phosphorus and potassium content of plant growing wheat, depending on the level of initial contamination* of grey forest soil with oil (2017).

\begin{tabular}{|c|c|c|c|c|c|c|}
\hline \multirow{3}{*}{$\begin{array}{l}\text { Oil dose, } \\
\mathrm{l} / \mathrm{m}^{2}\end{array}$} & \multicolumn{6}{|c|}{ Total content for absolutely dry weight, \% } \\
\hline & \multicolumn{3}{|c|}{ grain } & \multicolumn{3}{|c|}{ srtaw } \\
\hline & nitrogen & phosphorus & potassium & nitrogen & phosphorus & potassium \\
\hline 0 -- control & 2.24 & 0.87 & 0.70 & 0.44 & 0.17 & 0.96 \\
\hline 10 & 2.27 & 0.88 & 0.71 & 0.44 & 0.17 & 0.96 \\
\hline 20 & 2.30 & 0.89 & 0.74 & 0.44 & 0.18 & 0.98 \\
\hline 40 & 2.32 & 0.90 & 0.75 & 0.45 & 0.18 & 0.99 \\
\hline $\mathrm{MED}_{05}$ & $\mathrm{~F}<\mathrm{F}_{05}$ & $\mathrm{~F}<\mathrm{F}_{05}$ & $\mathrm{~F}<\mathrm{F}_{05}$ & $\mathrm{~F}<\mathrm{F}_{05}$ & $\mathrm{~F}<\mathrm{F}_{05}$ & $\mathrm{~F}<\mathrm{F}_{05}$ \\
\hline
\end{tabular}

Note: * -- Soil contaminated in 2004.

benzo[g,h,i]perylene, among which the first two compounds have the highest carcinogenic potential. There is a close relationship between the doses of oil and the homologues of benzo(a)pyrene. For example, if the content of dibenzo(a,h)anthracene in the grain has increased by almost 40 times in the case of an oil dose of $20 \mathrm{l} / \mathrm{m}^{2}$, and in the case of soil contamination by a dose of $40 \mathrm{l} / \mathrm{m}^{2}$, it has increased 87 times in comparison with the control level (uncontaminated soil). The content of other substances in wheat grain -- indeno[1,2,3-c,d]pyrene -- was slightly less correlated with the doses of oil: if a single dose of oil $\left(20 \mathrm{l} / \mathrm{m}^{2}\right)$ increased its content by a factor of 10 , the double dose $\left(40 \mathrm{l} / \mathrm{m}^{2}\right)$ was 15 times.

\section{Conclusion}

The sharp increase in carcinogenic substances in spring wheat grains grown 13 years after oil contamination with doses of 20 and $40 \mathrm{l} / \mathrm{m}^{2}$ is of great concern. Therefore, determining the degree of detoxification of oil-contaminated soils by the content of basic nutrients in plants and yield is clearly insufficient to objectively assess the fertility recovery of such soils. For objective assessment of agroecological safety of oilcontaminated soils it is necessary to carry out further in-depth studies of the chemical composition of growing vegetation, first of all, regarding the presence of carcinogenic substances in them. 


\section{References}

[1] Vasiliev, A.V., Bykov, D.E., Pimenov, A.A. (2015). Ecological monitoring of soil pollution with oil-containing wastes. Izvestiya Samara Scientific Center of the Russian Academy of Sciences, no.4, pp. 269--272.

[2] Voevodina, T.S., Rusanov, A.M., Vasilchenko, A.V. (2015). Influence of oil on chemical properties of black soil of the ordinary southern Urals. Vestnik Orenburg State University, no. 10, pp. 157--160.

[3] Gilyazov, M.Y., Yapparov, A.H., Gaisin, I.A. (2009). Oil-contaminated soils of the Republic of Tatarstan and methods of their reclamation. Kazan: Center for Innovative Technologies, $244 \mathrm{p}$.

[4] Gilyazov, M.Yu., Ravzutdinov, A.R. (2014). Crop yields depending on the level and age of oil pollution of gray forest soil. Grain economy of Russia, No.2 (32), pp. 8--11.

[5] Huseynov, D.M. (1966). Study and application of the oil-growth substance (NGR) in crop. Oil fertilizers and stimulants in agriculture. Baku: Academy of Sciences of the AzSSR, pp. 7--11.

[6] Kireeva, N.A., Novoselova, E.I., Erokhin, N.I., Grigoriadi A.S. (2009). Accumulation of benz(a)pyrene in the system "soil-plant" at oil pollution and active sludge application. Vestnik Orenburg State University, no. 6(100), pp. 579--581.

[7] Mazunina, L.E. (2009). Features of anatomy and morphology of higher plants under conditions of oil pollution. Bulletin of Nizhnevartovsk State University, pp. 16--18.

[8] Solntseva, N.P. (1998). Oil production and geochemistry of natural landscapes. Moscow: Moscow State University, p. 376.

[9] Husainova, K.N. (2016). Hygienic assessment of the impact of oil products on the environment. Bulletin of the Kazakh National Medical University, no. 1, pp. 449--450.

[10] Saraeian, Z., Haghighi, M., Etemadi, N. et al. (2018). Phytoremediation effect and growth responses of cynodon spp. And agropyrondesertorum in a petroleumcontaminated soil. Soil and Sediment Contamination, vol. 27, no. 5, pp. 393--407.

[11] Uzoije, A.P., Agunwamba, J.C.(2011). Physiochemical Properties of Soil in Relation to Varying Rates of Crude Oil Pollution. Journal of Environmental Scienceand Technology, no. 4, pp. 313--323.

[12] Wang, Y., Feng, J., Lin, Q., Lyu, X., Wang, X., Wang, G. (2013). Effects of crude oil contamination on soil physical and chemical properties in Momoge wetland of China. Chinese Geographical Science, vol. 23, Iss. 6, pp. 708--715. 